\title{
Influences of Cutting Process Parameters on the CutTing Quality When Water Jet CutTing
}

\author{
Ivana Zetková, Štěpán Jeníček, Ondřej Hronek, \\ Vratislav Kotěšovec, Jiří Vrtáček, Miroslav Zetek
}
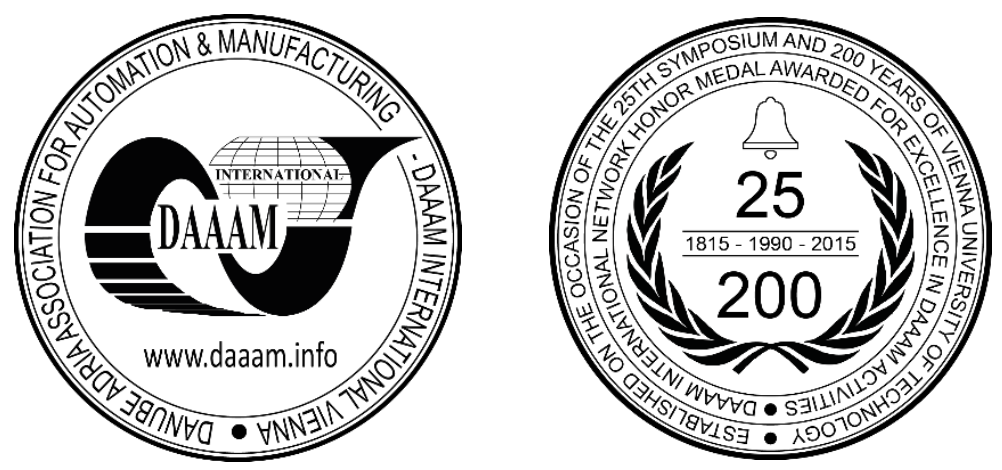

This Publication has to be referred as: Zetkova, I[vana]; Jenicek, S[tepan]; Hronek, O[ndrej]; Kotesovec, V[ratislav]; Vrtacek, J[iri] \& Zetek, M[iroslav] (2018). Influences of Cutting Process Parameters on the Cutting Quality when Water Jet Cutting, Proceedings of the 29th DAAAM International Symposium, pp.1286-1292, B. Katalinic (Ed.), Published by DAAAM International, ISBN 978-3-902734-20-4, ISSN 1726-9679, Vienna, Austria

DOI: $10.2507 / 29$ th.daaam.proceedings. 185

\begin{abstract}
The article analyses unconventional technology of water jet cutting and its impact on the cutting quality. A series of experiments were done to determine the effects of the used materials and their cut thickness on the final surface integrity, within the experimental program. Steels 1.1191 (12 050 according to ČSN) and 1.2379 (19 573 according to ČSN) were used for the experiment. Steel 1.1191 was selected, because this material is a standard for the steels machinability. Steel 1.2379 was chosen, because it belongs to a group of materials, which are difficult to machine. Therefore, it is possible to compare the cut quality of two steels with different properties. Also it was cut into the samples of different thickness. Thicknesses were chosen to make it clear, how the abrasive beam will handle a thick or thin workpiece wall. This article, the study of the integrity machined surface by progressive AWJ technology contributed to the influence evaluation of the material thickness during water jet cutting. The corrections for the cutting optimization and their influences to the cutting process were used in the experiment.
\end{abstract}

Keywords: water jet; cutting process; parameters change; quality of the cut

\section{Introduction}

The principle of water jet process is quite simple. Water comes from the tank through high pressure pumps into the transport system. High pressure pumps are capable to give water a pressure up to 6000 bar [1]. This pressure depends on the type and manufactures of the pumps. The transport system transport high pressure water into the chamber where the water is mixed with abrasive hard particles. Subsequently, the nozzle is already directs a full water jet on the workpiece surface. [2]

Abrasive water jet is suitable for cutting any compact material, from very thin foils up to a thickness of $300 \mathrm{~mm}$ or more. The most accurate cuts are achieved by bevel compensation technology at a thickness up to $50 \mathrm{~mm}$ or $100 \mathrm{~mm}-$ according to the machine construction. Rough cuts can be made even with a material thickness much greater than 100 $\mathrm{mm}$. [4] This technology is well suited for cutting thin steel with a request of smooth and very precise cut. Furthermore, the accuracy of water jet cutting can overcome laser cutting, because created edges are smother. 
Also there are no deformation (melting, burning) causes by heat energy and deformations. The water jet is not limited by the thickness, as is the laser or plasma cutting technology. However, the disadvantage is higher financial difficulty. The investment cost to the equipment exceeds the cost of plasma cutting equipment. But is lower than cost of laser equipment. [6] The operating costs are much higher compared to the laser. Mainly due to the price of the used abrasive. $[5]$

\subsection{Quality of the cut}

Generally valid standards for the evaluation of the surface topography by the AWJ technology have not yet been established or implemented. However, for many year has been a partition of achieved cutting qualities, which are referred from Q1 to Q5 (Fig. 1), where the quality of the cut Q1 is defined as the worth dividing cut and the Q5 as the best. Companies that use AWJ use this partition, but for each of them, differences can be found between each grade. Primarily, this is due to undefined parameters of precision and surface quality for individual stages.

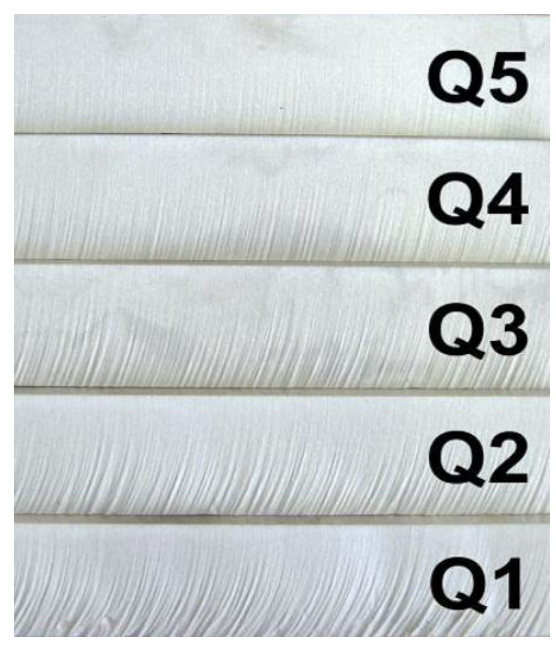

Fig. 1. Grades of the cutting quality [3]

\subsection{Technology of cutting optimization}

Tests were carried out on the machine WJ2830-2Z-Cobra-PJ60 from PTV. This manufactured has developed (implemented) a ProgressJet technology, material feed control - MFC and dynamic radius correction - DRC because of increasing speed, cutting accuracy and reducing production costs. The purpose of the experiments was to verify their suitability for producing the required samples, i.e. the effect of these technologies on the surface quality and dimensional accuracy.

ProgressJet is a cutting correction that removes the chamfer resulting from water jet cutting by tilting the nozzle. By ProgressJet are achieve vertical cuts and contributes to better shape accuracy of final product. The chamfers are created due to loss of cutting beam power during cutting process. This chamfers are not create thanks to the tilt nozzle, which is tilting up to $\pm 10^{\circ}$ in rotary axis (Fig. 2). First tilt direction is in the feed direction and the second is into the cutting surface (perpendicularly on feed direction). That is because of getting stronger and constant beam across the width of the cut. But this correction can be only used for cutting flat samples, not for slant cuts. This function is fully controlled by CNC system of the table. [8]
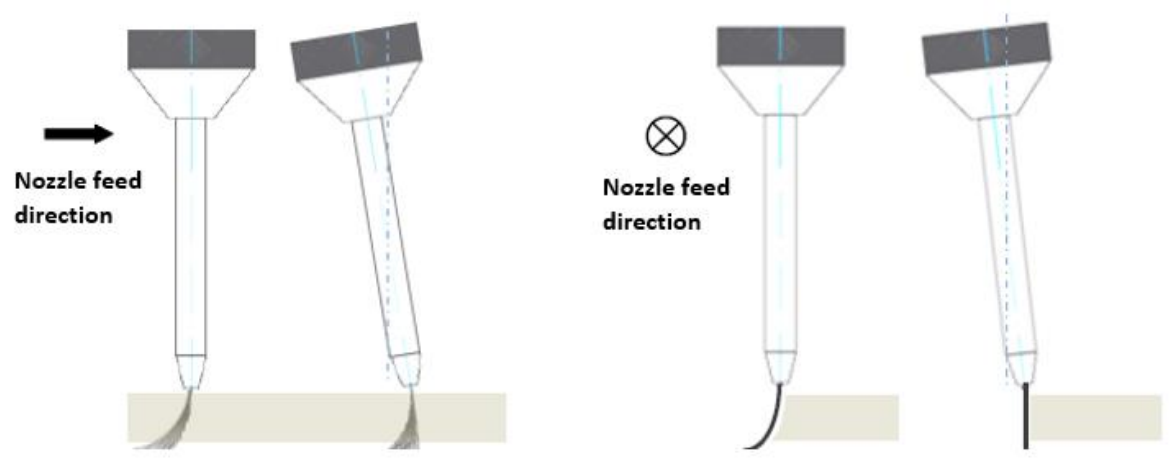

Fig. 2. Nozzle tilting when using ProgressJet 
Material feed control (MFC) attempts to prevent hints, undercuts and eradications. The value of beam speed is specific, because the beam width must be same for the entire cutting length. For example, when the beam approaches a radius or contour curve, the beam will slow down and hold at a reduced speed. Due to this reduction the beam width equals across the width. [8]

Dynamic radius correction (DRC) compensates width change gap cut by AWJ. The width of gap depends on the beam, which narrows and delays during different speed. Also this compensations are at the entry and exit from the material. The process in company is that the machine operator performs a test cut, which determines the "maximal diameter" of the beam. The system subtracts the estimated change in the diameter of the beam from this maximum. The system deducts this estimated value based on the test results. [8]

\section{Experiment}

The main goal of this experiment was to cut out a designed contour by abrasive water jet technology (Fig. 3). This shape was designed because the AWJ beam would cut not only the outer but also inner contour, the radius with a change of interpolation and a chamfer surface of $45^{\circ}$. Steels 1.1191 (12 050 according to ČSN) and 1.2379 (19 573 according to ČSN) were used for the experiment.

Steel 1.1191 was selected, because this material is a standard for the steels machinability. Steel 1.2379 was chosen, because it belongs to a group of materials, which are difficult to machine. Therefore, it is possible to compare the cut quality of two steels with different properties. Thickness of the experimental samples were $5 \mathrm{~mm} ; 10 \mathrm{~mm} ; 15 \mathrm{~mm}$ and 20 $\mathrm{mm}$. The thickness was chosen to make it clear how the abrasive beam will handle the different sample thickness.

The corrections were used for each sample (i.e. 2 samples at each thickness of the same material, but each cut by different process). The corrections are the machine's software offer to eliminated cutting errors - eliminating undercuts, beam thickness and slowing contour bends (more in chapter 1.2). Sixteen samples were made.
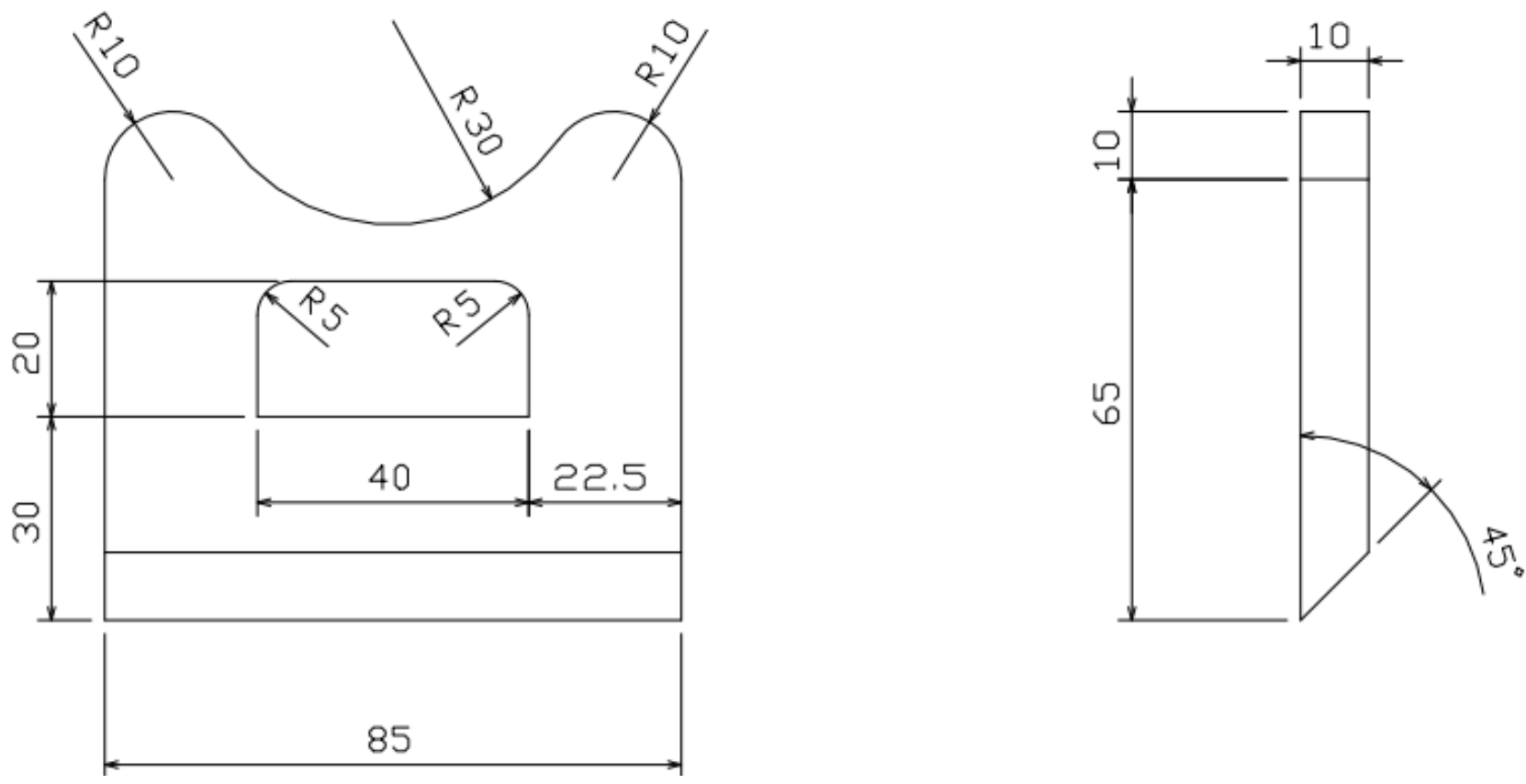

Fig. 3. Contour used during AWJ machining

The following parameters were used for all samples:

Test set:

- $\quad$ PTV JETS 3.8/60-COMPACT high pressure pump (max. operating pressure $415 \mathrm{MPa}$, max. flow 3,8 1/min)

- X-Y cutting table PTV WJ2830-2Z (working area $3000 \times 2000 \mathrm{~mm}$ )

- Cutting speed is continuously adjustable in the range of $0-20 \mathrm{~m} / \mathrm{min}$ 
Experimental parameters:

- Working pressure [MPa]: 416

- Process abrasive: Australian garnet

- MESH: 80

- Abrasive mass flow - [g/min]: 300

- Water nozzle diameter [mm]: 0,33

- Abrasive nozzle [mm]: 0,889

- Distance between nozzle and standoff [mm]: 4

- $\quad$ Required quality of the cut: Q5

These parameters were constant during experiment. The cutting speed (feed of beam) is automatically generated according to the type of material, the required quality of the cut and material thickness. It is not possible to choose exactly type of steel in the SW used for cutting, it have to choose only "steel".

Variable cutting parameters:

- Thickness [mm] : 5;10;15 and 20

- Material: 1.1191 (12 050 according to ČSN) and 1.2379 (19 573 according to ČSN)

- Machine options: Corrections on and off - ProgressJet, MFC, DRC [8]

\subsection{Sample clamping}

The (Fig. 4) shows the clamping of the workpiece by four clamps to the working table on the water surface. High fix attachment is important due to the quality of the cut. During AWJ process, high forces acts on the workpiece and it is undesirable for the sample movement. Either during the shot of the contour cutting. On the left (Fig. 4) figure is a tilt cutting head during cutting slant surface.

The program always started with this cut. Then the program returned to the starting position. The magnets were attached to the workpiece after this cut. Magnets prevents the sample being sifted into the tank, eventually cutting the work grid (Fig. 4). They also stabilized the cutting part of workpiece. Due to this stabilization, there was not any unwanted movement at the moment, when the beam was approaching the contour, and the cut pieces was then attached to the workpiece with only a very small part.
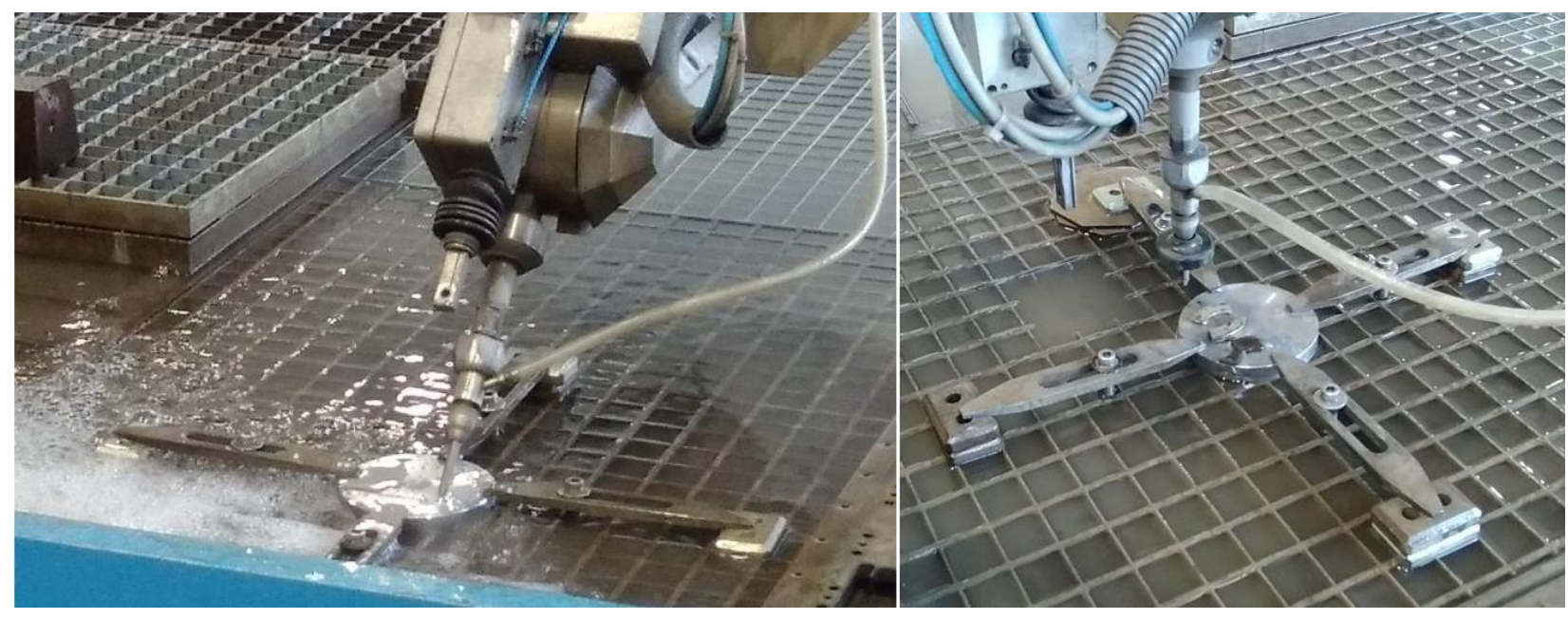

Fig. 4. Sample clamping

\subsection{Results}

Measurement was performed on a Multicheck PC500 microscope. The final dimension was obtained by the difference of coordinates and was rounded to $0.01 \mathrm{~mm}$.

Three dimensions were measured: outer dimension $85 \mathrm{~mm}$ and two inner $20 \mathrm{~mm}$ and $40 \mathrm{~mm}$. For detection of a bevel, the top and bottom edges were measured. The measurements were made because of the accuracy of AWJ process. 


\begin{tabular}{|c|c|c|c|c|c|c|c|c|c|}
\hline \multicolumn{10}{|c|}{ Steel 1.1191 (12 050 according to ČSN $)$ - measured values } \\
\hline \multirow{2}{*}{\multicolumn{2}{|c|}{$\begin{array}{c}\text { Thickness }[\mathrm{mm}] \\
\text { Correction }\end{array}$}} & \multicolumn{2}{|c|}{5} & \multicolumn{2}{|c|}{10} & \multicolumn{2}{|c|}{15} & \multicolumn{2}{|c|}{20} \\
\hline & & On & Off & On & Off & On & Off & On & Off \\
\hline \multirow{3}{*}{ A-85mm } & Top edge & 84.41 & 84.52 & 84.46 & 84.56 & 84.50 & 84.57 & 84.63 & 84.67 \\
\hline & Bottom edge & 84.69 & 85.17 & 84.71 & 85.25 & 84.65 & 85.05 & 84.88 & 85.25 \\
\hline & Difference & 0.28 & 0.65 & 0.25 & 0.69 & 0.15 & 0.48 & 0.25 & 0.58 \\
\hline \multirow{3}{*}{$\mathrm{B}-40 \mathrm{~mm}$} & Top edge & 40.73 & 40.63 & 40.70 & 40.54 & 40.84 & 40.49 & 40.62 & 40.44 \\
\hline & Bottom edge & 40.41 & 40.02 & 40.44 & 39.97 & 40.62 & 39.91 & 40.37 & 39.90 \\
\hline & Difference & 0.32 & 0.61 & 0.26 & 0.57 & 0.22 & 0.58 & 0.25 & 0.54 \\
\hline \multirow{3}{*}{ C- $20 \mathrm{~mm}$} & Top edge & 20.83 & 20.63 & 20.80 & 20.62 & 20.78 & 20.49 & 20.73 & 20.41 \\
\hline & Bottom edge & 20.53 & 19.98 & 20.48 & 19.95 & 20.51 & 19.78 & 20.36 & 19.78 \\
\hline & Difference & 0.30 & 0.65 & 0.32 & 0.67 & 0.27 & 0.71 & 0.37 & 0.63 \\
\hline
\end{tabular}

Table 1. Dimensions of each samples - steel 1.1191

\begin{tabular}{|c|c|c|c|c|c|c|c|c|c|}
\hline \multicolumn{10}{|c|}{ Steel 1.2379 (19 573 according to ČSN) - measured values } \\
\hline \multirow{2}{*}{\multicolumn{2}{|c|}{$\begin{array}{c}\text { Thickness }[\mathrm{mm}] \\
\text { Correction }\end{array}$}} & \multicolumn{2}{|c|}{5} & \multicolumn{2}{|c|}{10} & \multicolumn{2}{|c|}{15} & \multicolumn{2}{|c|}{20} \\
\hline & & On & Off & On & Off & On & Off & On & Off \\
\hline \multirow{3}{*}{$\mathrm{A}-85 \mathrm{~mm}$} & Top edge & 84.34 & 84.36 & 84.31 & 84.42 & 84.41 & 84.47 & 84.83 & 84.55 \\
\hline & Bottom edge & 84.67 & 85.06 & 84.56 & 84.95 & 84.83 & 85.31 & 84.84 & 85.29 \\
\hline & Difference & 0.33 & 0.70 & 0.25 & 0.53 & 0.42 & 0.84 & 0.01 & 0.74 \\
\hline \multirow{3}{*}{$\mathrm{B}-40 \mathrm{~mm}$} & Top edge & 40.77 & 40.64 & 40.81 & 40.56 & 40.84 & 40.61 & 40.63 & 40.53 \\
\hline & Bottom edge & 40.44 & 40.05 & 40.55 & 40.02 & 40.57 & 40.06 & 40.32 & 39.93 \\
\hline & Difference & 0.33 & 0.59 & 0.26 & 0.54 & 0.27 & 0.55 & 0.31 & 0.60 \\
\hline \multirow{3}{*}{$\mathrm{C}-20 \mathrm{~mm}$} & Top edge & 20.6 & 20.86 & 20.86 & 20.57 & 20.85 & 20.55 & 20.65 & 20.42 \\
\hline & Bottom edge & 20.51 & 19.92 & 20.61 & 19.96 & 20.52 & 19.92 & 20.32 & 19.76 \\
\hline & Difference & 0.09 & 0.94 & 0.25 & 0.61 & 0.33 & 0.63 & 0.33 & 0.66 \\
\hline
\end{tabular}

Table 2. Dimensions of each samples - steel 1.2379

From the results it is possible to evaluated, that the cutting process with corrections causes the smaller chamfer compared to the cutting without corrections. However, the size of the chamfer is approximately the same, whether it is a sample of $5 \mathrm{~mm}$ or $20 \mathrm{~mm}$. Furthermore, it is obvious that the ideal dimensions have not been achieved by AWJ technology. The deviations are in the order of $0.1 \mathrm{~mm}$ from ideal dimensions. This fact is for all thickness of experimental samples. The difference is only that the thickest samples at area of top edge are closer to the ideal size. But on the other hand, the lower dimensions are delays from the ideal dimensions. It is also possible to see, that the upper dimensions of steel 1.1191 is closer to an ideal size of $80 \mathrm{~mm}$ with one exception. Lower sample sizes of $5 \mathrm{~mm}$ and $10 \mathrm{~mm}$ have a similar difference between the top and the bottom dimensions. Samples of thickness $15 \mathrm{~mm}$ made from 1.1191 have differences less than samples made from 1.2379. For the samples of thickness $20 \mathrm{~mm}$, steel 1.2379 has the same size at the top and bottom area. The thickness of samples influences the time process. Time increases linearly with the sample thickness (Table 3). Cutting time with turned correction is process time higher. If the sample is thicker, the time intensity for cutting process is higher compared to the cutting without corrections - curves are delayed. Cutting into different materials was time-consuming as the "Cutting Parameters Setting" Can only be set to "Steel". So the software of machine calculates the same cutting speed for booth steels 1.1191 and 1.2379.

\begin{tabular}{|c|c|c|}
\hline Sample thickness $[\mathrm{mm}]$ & Corrections off $\mathrm{t}[\mathrm{min}, \mathrm{s}]$ & Correction on $\mathrm{t}[\mathrm{min}, \mathrm{s}]$ \\
\hline 5 & $0: 02: 03$ & $0: 02: 08$ \\
\hline 10 & $0: 04: 12$ & $0: 04: 36$ \\
\hline 15 & $0: 06: 34$ & $0: 07: 28$ \\
\hline 20 & $0: 09: 08$ & $0: 10: 36$ \\
\hline
\end{tabular}

Table 3. Time of contour cutting 


\subsection{Visual quality control}

Visual quality control is the basic quality control of water jet cutting. It is easy and quick to see what surface quality has been achieved under this visual control. There are five grades Q1 (worst) - Q5 (best). Quality grade is determined by comparing the cut sample with the quality standard. Depends on how deep marks the slowing beam leave on cut surface. For a thickness $20 \mathrm{~mm}$ (Fig. 5) the Q5 surface quality was achieved for 1.2379, which was cut without corrections. Quality Q4 was achieved for 1.1191. It was cutting process without corrections. The Q3 quality was achieved with two remaining samples during cutting with corrections.
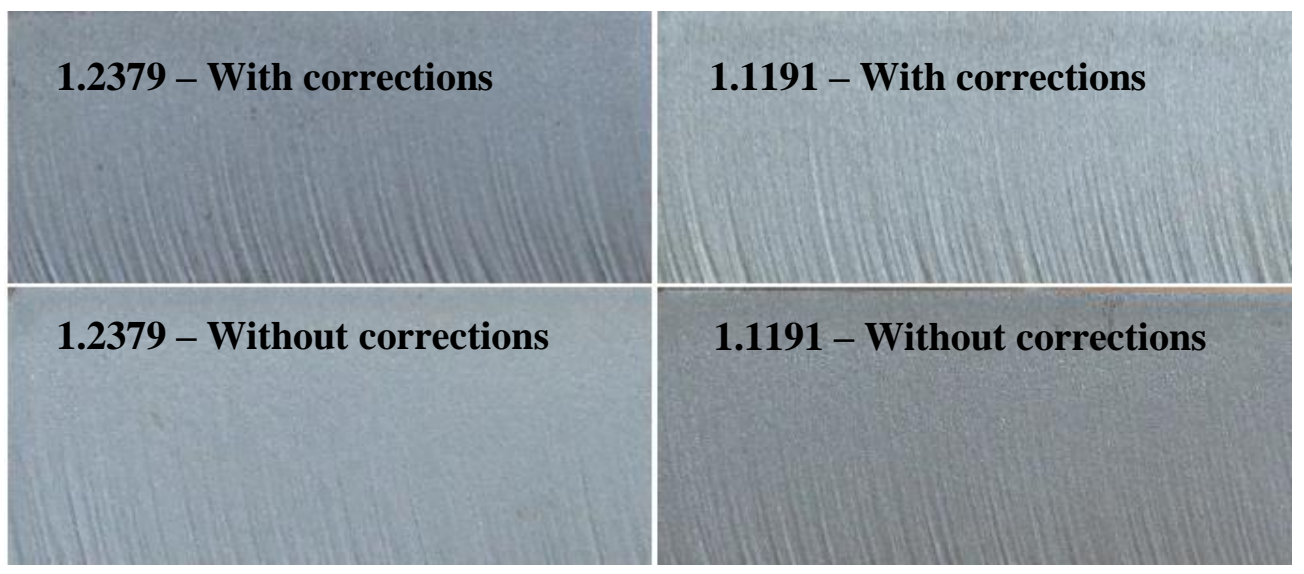

Fig. 5. Visual quality control - cut with and without corrections for tested steel of thickness $20 \mathrm{~mm}$

It cannot be said that the quality of the samples is obvious Q5 for a thickness $20 \mathrm{~mm}$. The surface quality is very close to the Q5, between Q4 and Q5. For samples of thickness $10 \mathrm{~mm}$ can be seen that the material 1.2379 has deeper grooves and higher surface quality Q3, compared to the 1.1191, which shows a higher surface quality between Q4 and Q5. Quality Q3 is shown in all four samples of thickness $5 \mathrm{~mm}$. There is no apparent difference in quality between different materials or on and off corrections.

Since the Q5 has been selected, only few samples reached required quality. In contrast, many samples reached Q3 and Q4 surface quality. Better surface quality could be achieved by different cutting speed that is less than calculated by the software. But it is only an estimate. More graspable and specific surface information can be seen by roughness measurement.

\section{Conclusion}

The quality of the cut with dimensional precision and visual inspection of samples were evaluated in the experiment. By an AWJ process the bevels were created on the cut surface, as evidenced by the measured values in three dimensions. The difference between the top and bottom dimensions was $0.53-0.70 \mathrm{~mm}$ (expect for a few exceptions) when the ProgressJet offset was disabled. A significant reduction in bevels was achieved when cutting with ProgressJet correction enabled. The differences between top and bottom dimensions was $0.25-0.33 \mathrm{~mm}$.

The type of material had minimal effect on accuracy. The samples thickness did not affect the accuracy of the dimensions. In the visual quality control, the Q5 required just few samples. The quality was Q3 and Q4 in most cases. Worse surface quality was achieved during angled cuts, compared to the straight cuts of the same thickness. For the inner contour at the bottom, the right angle is cut and also better quality was achieved with corrections. While the radius $5 \mathrm{~mm}$ is better during cutting without corrections. The thicker sample causes lower cut quality at the bottom of the inner contour. The influences of material on surface quality is showed for a sample thickness $20 \mathrm{~mm}$ in radius $5 \mathrm{~mm}$, where are significant traces of the beam at 1.1191. Small radii like this or right angles can be cut with AWJ, but with thicker specimen $10 \mathrm{~mm}$, the beam creates a radius with a deflection from the ideal contour of rectangle at right angles. Sample thickness influences interpolation change where either a depression or a bump is formed at the bottom of the cut. Thicker sample means the more significant unevenness on the top of the cut. It is preferable not to use corrections for these interpolation changes. Before cutting it is important to think about how looks the shape of the cutting contour. From that point it is necessary to decide whatever the corrections will be off or on during AWJ process.

\section{Acknowledgments}

The present contribution has been prepared under project LO1502 'Development of the Regional Technological Institute' under the auspices of the National Sustainability Programme I of the Ministry of Education of the Czech Republic aimed to support research, experimental development and innovation. 


\section{References}

[1] https://www.flowwaterjet.cz/Prectete-si-vice/Jak-funguje-vodni-paprsek.aspx\#tbasics

[2] Kumar, Manish. Controlled High Pressure Slurry Injection In Water Jetting Applications-A New Approach. India, 2002.]

[3] Suchánek, Libor. Nekonvenční metody obrábění při výrobě malých otvorů. Plzeň, 2014.

[4] http://www.flowwaterjet.com/Resources/Ask-Dr-Hashish-a-Question, (2016). Ask Dr. Hashish - Dr. Mohamed Hashish is the inventor of the abrasive waterjet and an expert in high pressure design and tribology., Accessed on: 2016-08-12

[5] http://www.esabna.com/us/en/education/blog/what-is-the-best-way-to-cut-steel-plate.cfm, (2013). What Is The Best Way To Cut Steel Plate, ESAB Knowledge Center, Accessed on: 2016-08-12

[6] Roubíček M., (2016). Criteria for the choice of method and trends in materials thermal cutting. Kriteria volby metody a trendy tepelného dělení materiálu, Available from: http://www.airliquide.cz/file/otherelement/pj/roubicek49122.pdf, Accessed: 2016-08-10

[7] Jenicek, S.; Kotesovec, V.; Kalina, T. \& Masek, B. (2016). Use of Waterjet in Manufacturing Test Bars of HighStrength Steels, Proceedings of the 27th DAAAM International Symposium, pp.0219-0224, B. Katalinic (Ed.), Published by DAAAM International, ISBN 978-3-902734-08-2, ISSN 1726-9679, Vienna, Austria DOI: 10.2507/27th.daaam.proceedings.

[8] PTV (2016). Manuály ke stroji PTV Jets 3.8/60-Compact, PTV, spol. s r.o 